\title{
3D printing of medicinal products and the challenge of personalized therapy
}

Lucia Zema, Alice Melocchi, Alessandra Maroni, Andrea Gazzaniga

Università degli Studi di Milano, Dipartimento di Scienze Farmaceutiche, Sezione di Tecnologia e Legislazione Farmaceutiche “M.E. Sangalli”, Via G. Colombo 71, 20133 Milan, Italy; lucia.zema@unimi.it; alessandra.maroni@unimi.it; alice.melocchi@unimi.it; andrea.gazzaniga@unimi.it

Corresponding author: Lucia Zema; Telephone:+39-02-503-24654; lucia.zema@unimi.it 


\begin{abstract}
By 3D printing, solid objects of any shape are fabricated through layer-by-layer addition of materials based on a digital model. At present, such a technique is broadly exploited in many industrial fields because of major advantages in terms of reduced times and costs of development and production. In the biomedical and pharmaceutical domains, the interest in $3 \mathrm{D}$ printing is growing in step with the needs of personalized medicine. Printed scaffolds and prostheses have partly replaced medical devices produced by more established techniques and, more recently, 3D printing has been proposed for the manufacturing of drug products. Notably, the availability of patient-tailored pharmaceuticals would be of utmost importance for children, elderly subjects, poor and high metabolizers and individuals undergoing multiple drug treatments. 3D printing encompasses a range of differing techniques, each involving advantages and open issues. Particularly, solidification of powder, extrusion and stereolithography have been applied to the manufacturing of drug products. The main challenge to their exploitation for personalized pharmacological therapy is likely to be related to the regulatory issues involved and to implementation of production models that may allow to efficiently turn the therapeutic needs of individual patients into small batches of appropriate drug products meeting preset quality requirements.
\end{abstract}

Keywords: drug delivery systems, solid dosage form, extrusion, oral drug delivery, controlled release, 3D printing, personalized medicine, solidification of powder, fused deposition modeling, stereolithography 


\section{Table of Contents}

1 Introduction

2 Personalization

2.1 Personalized medicine

2.2 Personalized therapy

3 3D printing of drug products

3.1 Highlights on solidification of powder

3.2 Highlights on extrusion

3.3 Highlights on stereolithography

4 Regulatory perspectives

References

\section{Abbreviations:}

2D, two dimensional

3D, three dimensional

ABS, acrylonitrile butadiene styrene

API, active pharmaceutical ingredient

ASTM, American Society for Testing Materials

CAD, computer-aided design

DDS, drug delivery system

DPPO, diphenyl (2,4,6-trimethylbenzoyl) phosphine oxide

EC, ethyl cellulose

EDTA, ethylenediaminetetraacetic acid

EVA, ethylene vinyl acetate

FDA, Food and Drug Administration

FDM, fused deposition modeling 
GRAS, generally recognized as safe

HIPS, high impact polystyrene

HME, hot melt extrusion

HPC, hydroxypropyl cellulose

HPMC, hydroxypropyl methyl cellulose

IM, injection molding

MCC, microcrystalline cellulose

PCL, poly-e-caprolactone

PEG, polyethylene glycol

PEGDA, poly (ethylene glycol) diacrylate

PLA, poly (1-lactic acid)

PLGA, poly(lactide-co-glycolide)

PVA, polyvinyl alcohol

PVP, polyvinyl pyrrolidone

SLA, stereolithography

SLS, sodium lauryl sulfate

TEC, triethyl citrate

TPU, thermoplastic polyurethane

UV, ultraviolet 


\section{D printing glossary:}

- ADDITIVE MANUfACTURING: the process of joining materials to fabricate objects from 3D model data, usually layer by layer

- COMPUTER-AIDED DESIGN: refers to the use of computer systems to assist in the creation, modification or optimization of 3D drawings

- EXTRUSION: 3D printing process that involves layer by layer deposition of molten/softened or liquid/semisolid materials through a syringe or a nozzle

- FUSED DEPOSITION MODELING: 3D printing technique that involves the use of one or more filaments, generally based on a thermoplastic material, which are extruded and deposited in a molten/softened state layer by layer

- RAPID PROTOTYPING: production of a prototype/scale model of a physical object/assembly using 3D computer-aided design data

- RESOLUTION: degree of conformity of a 3D printed object to the electronic model by which it was generated

- SOLIDIFICATION OF POWDER: 3D printing technique that involves the distribution of thin layers of powder selectively joined by using drops of a liquid binder

- STEREOLITOGRAPHY: 3D printing technique that involves the use of a UV laser to cure a photo-reactive resin, contained in a vat, layer by layer into a solid object

- .stl FILE: file generated by a computer-aided design program that contains all the data describing the layout of a $3 \mathrm{D}$ object and it is the most commonly used file format for $3 \mathrm{D}$ printing

- SUBTRACTIVE MANUFACTURING: process in which 3D objects are fabricated by successively cutting material away from a solid block of the latter 


\section{Introduction}

3D printing enables the construction of solid objects of any shape through layer-by-layer addition of materials (additive manufacturing) based on a digital model ${ }^{1,2}$. In contrast to traditional subtractive manufacturing, which consists in successively cutting away material from a starting block in order to build up the final object, 3D printing allows production to be carried out with no waste of materials and no need for their disposal. Because objects are constructed automatically, according to preset digital models, relevant preliminary geometry study, production planning and manual manufacturing steps can be limited or avoided. This results in major advantages in terms of reduced times and costs, irrespective of the extent of complexity of the item shape. The degree of conformity of an object to the electronic model by which it was generated (i.e. resolution) basically depends on the thickness of the single layers deposited, and can thus be enhanced through proper modulation of this parameter.

3D printing encompasses a range of techniques differing from each other in the nature of the substrate (e.g. ceramics, metals, polymers, composites), deposition mode, mechanism of layer formation, printer employed and characteristics of the final product (e.g. morphology, texture, surface, thermal/mechanical/conductivity properties). According to the ASTM, these techniques are classified based on the additive process involved (Table 1$)^{3}$.

Independent of the specific technique applied, 3D printing processes generally entail common steps: the creation of a CAD file, its conversion into a .stl file, which will be transferred to the equipment, the printer set-up and proper fabrication of the object, its removal from the build plate, postprocesses and final cleaning step if needed (Figure 1$)^{1,2}$. The entire manufacturing process occurs as a single step under computer control, thus avoiding intermediate stages of production and any manual task. Any change in the final object design can be achieved by modifying the relevant CAD file. 


\section{Personalization}

The current popularity of $3 \mathrm{D}$ printing in various fields is often described as a new industrial revolution ${ }^{4,5}$. While in the last centuries industries were focused on mass-manufacturing, automation and standardization in order to reduce costs and increase profit, with the advent of $3 \mathrm{D}$ printing they are shifting to on-demand production of either a small number of objects or even one object at a time (small batches), possibly customized, at affordable prices. Products characterized by complex geometries can also be fabricated and real-time modified to meet individual needs at little or no extra costs. 3D printing is spreading throughout all manufacturing stages of production, from the prototyping step to the fabrication of consumer products. By shortening the design, manufacturing and production cycle, thus simplifying the manufacturing chain, this new technology has brought the site of object fabrication closer to that of demand. Moreover, it has proved effective as a rapid prototyping tool useful to evaluate the form, fit and function of many objects before their production on a large scale. Finally, because items are fabricated upon request, waste and inventory can be reduced, and issues related to overproduction are circumvented.

\subsection{Personalized medicine}

Within the healthcare field, 3D printing has grown in step with the concept of personalized medicine, which has been attracting more and more attention in the last ${ }^{6-10}$. Personalized medicine generally consists in tailoring medical treatments to the characteristics, needs and preferences of each single patient, and it involves purposely run diagnosis, therapy and follow-up. The concept could be extended to include pre-emptive medicine aimed at reducing the risk of diseases a subject has shown susceptible to, by changing his lifestyle, diet and habits and by advising him on the use of peculiar supplements or drugs. Personalized medicine is not actually a new idea: physicians have noticed over time that patients with similar symptoms may have different illnesses, and that medical treatments may work in some subjects while not being as much effective in others apparently suffering from the same disease. Recent advances in various medical and biomedical fields, from 
genomics to imaging, have already allowed patients to be treated and monitored more properly, in closer and closer agreement with their individual needs. By way of example, genetic tests are employed prior to diagnosis, thereby enabling earlier intervention, more efficient drug selection and increased safety. Indeed, the goal of personalized medicine is to drive clinical decision-making by distinguishing in advance those patients who are most likely to benefit from a given treatment from those who would incur costs and side effects without gaining equivalent benefits. In this respect, 3D printing could provide the answer and instrument for moving from mass-production based on the one-size-fits-all approach to manufacturing of small batches of individually developed products that can be modified in real time and possibly fabricated at the point of care ${ }^{11-14}$.

\subsection{Personalized therapy}

In the medical field, 3D printing was initially employed by surgeons as an aid in creating 3D models of patients to better visualize their anatomy, particularly in the case of individuals with unique structures or anomalies, which would require complex surgeries ${ }^{15-16}$. With respect to tissue engineering, medical devices, especially scaffolds and prostheses, currently represent one of the most interesting manufacturing applications of $3 \mathrm{D}$ printing ${ }^{17}$. This technique has partially replaced more established ones (e.g. solvent casting and particulate leaching, membrane lamination, molding) since it enables fabrication, starting from biocompatible materials, of items perfectly fitting the anatomical characteristics of the patient as highlighted by diagnostic imaging tools (e.g. X-ray, computed tomography, nuclear magnetic resonance). Scaffolds are intended for different functions, such as space filling, 3D structures that organize proliferating cells into a desired tissue, in situ vehicles for the delivery of active molecules (e.g. antibiotic or anti-inflammatory drugs, growth factors). The ability to fabricate a 3D structure characterized by pre-determined pore dimensions, distribution and interconnectivity was proved to be critical for cell adhesion and growth. Because 3D printing yields finished items with a high-resolution microstructure, it turns out 
especially promising in this area ${ }^{18-21}$. Only in the new millennium, 3D printing was proposed and exploited for the manufacturing of drug products ${ }^{13,14,22-25}$.

The availability of custom-made pharmaceuticals, conceived to meet the individual needs of a single patient, would be of special interest for instance to personalize the dose of the conveyed drug, enable co-administration of drugs in multi-therapies, avoid the use of specific excipients involved in intolerances, such as lactose or sucrose, change the flavor or ease. Particularly, patient-tailored products could be of utmost importance for children, elderly subjects, poor and high metabolizers and individuals who are taking multiple medicines that may interact with each other. In the field of personalized medication, sustainability, patentability and ability to produce at lower costs are only some of the several advantages that could justify the interest in $3 \mathrm{D}$ printing. Therapy personalization itself was identified as a tool for reducing the healthcare system expenses. The limited room required to set-up a $3 \mathrm{D}$ printing facility and the real-time production that is made possible by this technology may overcome the need for storage and long-term stability studies of finished products, which could extemporaneously be fabricated upon request. Within hospital and compounding pharmacies, 3D printing may fully innovate galenical practice, especially impacting on clinical trials and treatment of small groups of patients (e.g. people suffering from rare diseases). Moreover, it would allow release targets (e.g. controlled release), which are not yet feasible by compounding, to successfully be addressed. In the prospect of industrial production, 3D printing would enable continuous manufacturing, of high current interest, by dramatically simplifying downstream production ${ }^{26}$. Notably, 3D printing could easily be adapted not only to the manufacturing of small batches but also to that of large ones, by making more printers work in parallel or designing next-generation equipment provided with multiple printing sources.

\section{3D printing of drug products}

The interest in exploitation of 3D printing within the pharmaceutical field was promoted by the development of low-cost desktop versions of printers that has made this technology widely 
accessible for use in lab settings. Currently, the research activity in this specific area is mainly focused on evaluating the potential of 3D printing as an alternative approach to fabrication of drug products and as a tool for attaining innovative DDSs with unique design, composition and performance features. For example, 3D polymeric templates having a complex structure, in which a gel-based drug-containing preparation could be cast and cured, were proposed for the molding of products $^{27}$. Moreover, 3D printing was employed to fabricate cylindrical-shaped ABS containers, having two holes placed in different positions, to be filled with a drug formulation. By these systems, zero-order release kinetics would be attained avoiding the typical initial burst effect ${ }^{28}$. Rather than pursuing specific therapeutic goals, however, the research activity seems to be intended to highlight the versatility of the new technology, thus promoting its use for personalization of therapy.

Apart from the patent area, which is quite broad in scope with respect to $3 \mathrm{D}$ printing of drug products, the use of three specific techniques was actually reported in the scientific literature and, even if in rather few applications, undertaken in the industrial production: 3D printing based on solidification of powder, extrusion and, more recently, stereolithography. By way of example, a number of 3D printed drug products proposed in the scientific literature are depicted in Figure 2. These examples clearly show the degree of freedom dire that can be achieved in terms of shape (e.g. spherical, cylindrical, pyramidal, cubic), design (e.g. solid, hollow, pierced, polo, multilayer, coated, multi-compartment, gradient systems and relevant combinations) and composition (i.e. type of ingredients and their distribution within the product). In particular, one of more drugs can be included in whatever layer, compartment or part of the printed item. It is indeed known that, if compared with traditional manufacturing processes, 3D printing mainly offers the advantage to yield complex drug products within a single step, thus reducing the process time and the equipment needed (e.g. production and coating of the core in a single stage $)^{13,14,22,23,29}$. 
3D printing techniques currently employed for drug product manufacturing will briefly be discussed, highlighting the peculiar advantages, still open challenges and main applications proposed. A general outline of the relevant equipment is reported in Figure 3.

\subsection{Highlights of solidification of powder}

$3 \mathrm{D}$ printing based on solidification of powder was born as an evolution of traditional 2D printing and was first developed in the early ' $90 \mathrm{~s}$ at the Massachusetts Institute of Technology ${ }^{30-32}$. It involves deposition of a liquid formulation onto a powder bed to create bonds among the particles, and a 3D solid structure is constructed by successive layering of powders. Each layer is spread over a build plate and possibly compressed by a roller (Figure 3 ). The binding liquid is jetted according to a $2 \mathrm{D}$ pattern by one or more printer heads, thermal or piezoelectric, exploiting a technology that is close to ink-jet printing. The printer head system generally moves along the horizontal plane, whereas the build plate moves down along the vertical axis, so that successive new layers of powder can be deposited. At the end of the printing process, a drying step, which is generally carried out at room temperature, and the removal of free particles are required. In addition, the product may need to be heat-treated for elimination of residual solvents and achievement of mechanical resistance. Post-process treatments, and particularly disposal of any excess of powder, require suitable facilities and equipment since the presence of fine particles might be hazardous for human health.

3D printing based on solidification of powder holds potential for the manufacturing of drug products in that it involves the use of powdered materials and binding procedures, which are largely employed in the pharmaceutical field, especially for fabrication of solid dosage forms. Moreover, as with other manufacturing techniques, it is possible to adjust the characteristics of the product by changing the process parameters. Being correlated with the thickness of powder layers, the final resolution will strictly depend on the particle size: the smaller is the latter, the more detailed will be the structure achieved. However, flowability and cohesion issues as well as adhesion of the powder particles to the equipment may have to be faced. The powder formulation could contain the API and 
various excipients, including fillers, matrix formers (polymers) and release modifiers needed to define the final performance of the system.

Further critical process variables are the mode and speed of liquid deposition. This concerns the drop dimensions, movement of the nozzle and its distance from the powder bed as well as the jetting mode, which may be continuous under pressure, by drops, or alternate by means of a dropon-demand process. The liquid can either consist in a solution or a suspension, and may contain the drug along with release-controlling polymers, one or more binders, co-solvents, plasticizers and surfactants. Not only the composition but also the rheological characteristics of the liquid should attentively be considered. Moreover, in order to selectively enhance the formation of bonds among particles in specific areas of the powder bed, the 2D wetted pattern should strictly be defined. Items are often characterized by high porosity, which could represent an advantage, such as in the case of orally-disintegrating tablets, but also an issue for the handling of products ${ }^{33-35}$. The binder bleeding into the powder bed was identified as one of the most critical issues that may affect the product quality and performance. Indeed, bleeding along the vertical axis could cause not sufficiently resistant bonds to be created between two layers, thus reducing the mechanical strength of the final product. In addition, it may bring about poor surface quality, imprecise printing, worsened resolution and, in some cases, lack of release performance ${ }^{29,36}$. The ability to control the moisture content of the object during fabrication is also a factor that may affect further development of this technology, and the need for post-process operations could also be seen as a limitation.

3D printing based on solidification of powder was proposed for a number of applications that are summarized in Table 2. This technique enables fabrication of systems characterized by complex geometries and different microstructure, composition as well as surface features (Figure 2). Therefore, it was particularly exploited for obtaining of pierced and multilayer products or of items provided with internal cavities, void or containing free-flowing powder formulations ${ }^{34,36-38}$. The possibility of varying the spatial composition within a product, intended as the ability of introducing, with high resolution, different drugs or excipients (e.g. release modifiers, release- 
controlling polymers) in predetermined inner or surface regions, was also used for one-step fabrication of DDSs enabling combined release kinetics. Analogous results were obtained by switching between binders with different composition and properties.

3D printing based on solidification of powder allows high-precision dosing that is particularly important in the case of low-dosed drugs or for the achievement of concentration gradients within a matrix system possibly leading to zero-order release $\mathrm{s}^{39,40}$. Dissolution of a drug into the binding liquid was proposed in order to increase the bioavailability of poorly water-soluble compounds, although recrystallization phenomena may occur and lead to changes in the mechanical properties and release behavior of the product ${ }^{33}$. Besides stability issues, further critical aspects related to the drug load, limited availability of suitable binders, use of organic solvent and long process time still challenge the development of this printing technique over traditional manufacturing processes.

\subsection{Highlights of extrusion}

The $3 \mathrm{D}$ printing technique that exploits extrusion of molten/softened or semisolid materials as the additive process was only recently applied to fabrication of drug products, as a result of the availability of compact and relatively inexpensive equipment. Nevertheless, it has immediately shown a great potential in the field in view of well-evident similarities to pharmaceutical processing techniques such as extrusion (wet extrusion and HME) and IM. Moreover, the printing process is considered easier among customers, and can be run in do-it-yourself environments. Based on the starting materials employed, two different techniques may be identified, which make use of thermoplastic polymers, generally in the form of filaments, or of liquid/semisolid formulations, respectively.

FDM 3D printing involves the use of a thermoplastic material that is heated up and then deposited by a nozzle, in a semi-molten state, onto a build plate where it forms layers and solidifies (Figure 3). In most printers (e.g. MakerBot models), the same tractor wheel arrangement that drives polymeric filaments into the heated extrusion head also generates the extrusion pressure needed to 
make the melted/softened material flow. The extrusion head is carried by a plotting system that enables 2D movements, while the build plate allows the item to grow in the third dimension. While the nozzle orifice defines the diameter of the flowing material that is deposited, the vertical lowering of the build plate imparts the nominal thickness to each layer, and they both determine the final resolution of the printed object though this is also affected by the dilatometric behavior. More recently, printers with a reverse arrangement in which the build plate moves in the horizontal plane and the extrusion head rises vertically, so that the object is fabricated bottom up, were proposed (e.g. Printrbot). After deposition of the last layer, the removal of any support material (i.e. materials used to wrap or anchor the object under construction and prevent collapses) and other postprocesses (e.g. sandpapering, coating) may be needed to give the product its final aspect and properties. Some equipment are provided with multiple nozzles that allow more than one material to be processed at the same time, leading to fabrication of items having parts with different characteristics (e.g. color, composition), or the object and the support material to simultaneously be printed.

Starting materials for FDM are generally supplied in the form of filaments with defined shape and dimensions (i.e. diameter and diameter tolerances), which are produced by HME. Based on the broad demand for plastic products, filaments available on the market are mainly composed of ABS, PLA and HIPS. Exploitation of FDM in other areas, however, requires the development of new filaments composed of different materials. In this respect, not only the use of a range of polymers was explored, such as PVA, XT copolyester, nylon and TPU, but also diverse properties of filaments (e.g. color, resistance, flexibility, conductivity) were pursued. The current interest in this production technique is highlighted by the increasing number of companies focused on the manufacturing of new and high-quality filaments (e.g. TreeDFilaments) and, also, by the growing attention to safety issues, e.g. to the levels of ultrafine particles in the working area derived from the heating of PLA and ABS filaments ${ }^{47}$. However, no filaments based on pharmaceutical grade polymers are commercially available yet. In the beginning, research work was carried out using 
plastics (e.g. PLA, PVA) filaments and adding APIs by soaking or re-extrusion ${ }^{48-52}$. A few articles have recently been published on the formulation and extrusion of filaments based on pharmaceutical grade polymers such as acrylic and metacrylic acid copolymers, cellulose derivatives and $\mathrm{EVA}^{53-55}$. Moreover, the possibility of characterizing these filaments in terms of mechanical and surface properties (e.g. stiffness, brittleness, roughness) was taken into account, using the commercially available PLA filament as a reference ${ }^{26}$. Indeed, equipment used so far were conceived to work with plastic filaments available on the market. Therefore, printing issues such as break up of filaments and their wrapping around the loading gears, are likely to be encountered. Currently, the process of filament loading into the 3D printer was improved based on a trial and error approach, not only by adjusting the equipment configuration (e.g. compression force applied by the gears) but also by modifying the formulation of the filament under investigation, thus ameliorating its mechanical features ${ }^{54,56-58}$. The addition of external liquid lubricants (e.g. castor oil, glycerol, oleic acid, PEG 400) to help the loading process was also described. In the future, the experience gain in the production and characterization of filaments based on pharmaceutical-grade polymers will most likely promote the development and utilization of purposely-designed printers.

One of the main advantages offered by FDM in the manufacturing of drug products consists in the lack of solvents, which reduces time and costs of the process and may be beneficial to stability. The relatively high temperatures involved would limit microbial contamination. Moreover, they could promote interaction between the polymer and the drug conveyed, possibly leading to enhanced bioavailability through formation of solid dispersions or solutions ${ }^{26,59}$. As already observed with other hot-processes, the operating conditions involved by FDM could lead, by affecting porosity, to improved release profiles in the case of prolonged-release matrices if compared with traditional manufacturing by tableting. On the other hand, as occurring in the case of HME and IM, the processing temperatures could impact on the physical stability of the object, bringing about shrinkage and warpage phenomena, and on the chemical stability of the formulation components, either excipients or active ingredients. For this reason, an accurate selection of the starting materials 
is needed, and the availability of alternative polymeric filaments, which may differ in terms of physico-technological characteristics and processing conditions while allowing products with comparable performance to be obtained, could be of great interest. In addition to the physical properties of the starting materials (heat capacity, thermal conductivity, density, glass transition temperature and melt viscosity), process variables, such as loading pressure, feed rate, working temperature, deposition rate, layer height, infill percentage and number of shells, also affect the quality and resolution of the printed product ${ }^{22,49,56,58,60}$. Moreover, the configuration of the printer (e.g. heated or unheated build plate, presence of kapton tape and nozzle orifice diameter) and the environmental conditions, particularly when the equipment is not insulated, could influence the deposition and binding of successive layers, which impacts on the mechanical resistance of the fabricated structures.

As compared with products produced by solidification of powder, objects obtained by FDM are generally characterized by greater mechanical resistance and higher degree of geometrical freedom. The interest in products endowed with such versatility in design is testified by the recent foundation of startups and academic spinouts for their commercialization (e.g. Multiply Labs, FabRx). By way of example, empty hollow structures, which can be assembled into tightly closed capsules, were produced by this technique ${ }^{56}$. Moreover, FDM enables processing of more than one material at the same time thus allowing coated (i.e. shell-core structure) and multi-layered systems or items having a gradient composition to be fabricated, from which multiple-phase release kinetics can be achieved (Figure 2) $)^{54,58,61}$.

Since a clear layer deposition pattern can frequently be identified in the finished item, the surface smoothness of printed drug products often needs to be improved, for instance by using nozzles having a smaller orifice or reducing the layer height. Resolution issues are particularly challenging when the thickness and/or presence of details in the printed item represent a critical parameter (e.g. capsular devices, coated systems $)^{56,58}$. These issues were even more evident when using equipment wherein the position of the build plate has to be manually calibrated. In this respect, new 3D 
printers with automatic calibration sensors were recently developed. The release performance of the drug product can be modulated by changing not only the filament formulation but also the density of the deposition plot (e.g. infill percentage $)^{48,50,57,61}$. However, the main challenge of FDM is still represented by the scaling-up and the process time, which may not be compatible with large-scale production and advantageous with respect to more traditional manufacturing processes.

When extrusion starting from liquid and semisolid formulations is considered, Fab@Home and 3D Bioplotter are probably the most common printers that use solutions, dispersions, gels and pastes ${ }^{63}$ (Figure 3). In the case of 3D Bioplotter, initially developed to work in a sterile environment for the production of scaffolds, the layers are deposited by one or more syringes under defined conditions of temperature and pressure. On the other hand, Fab@home was the first multi-material 3D printer available on the market via an open source. Each syringe can independently and precisely (up to 1 $\mu \mathrm{L}$ ) control the deposition process through the movement of the inner plunger. One of the main advantages related to these types of equipment is the possibility of employing a large variety of materials, such as hydrogels, epoxy resins, chocolate and cheese, with no need for high temperatures. However, the possible use of organic solvent could be hazardous for human health whereas, in the best case, the use of water as the solvent involves the same critical issues described for 3D printing based on solidification of powder (e.g. microbial contamination, drug stability, control of moisture content during and after fabrication, drying procedures and final curing). The resolution and mechanical characteristics of the finished item, particularly friability and hardness, still represent a challenge for this technique. Moreover, the need for post-processes would also increase the overall production time. The use of gels and pastes as starting materials may result in shrinking or deformation of the printed product following the drying phase. The object may also collapse during fabrication if layers have not sufficiently hardened to withstand the weight of the next ones. Moreover, the technique is characterized by a low resolution as currently employed orifices have diameter in the $0.4-0.8 \mathrm{~mm}$ range.

The main applications of 3D printing based on extrusion are summarized in Table 3 and Figure 2. 


\subsection{Highlights of stereolithography}

As with 3D printing based on solidification of powder, which was developed starting from the inkjet technology, SLA results from upgrade of 2D lithography to cover the third dimension ${ }^{73,74}$. This printing process is based on solidification (curing) of successive layers of photosensitive liquid polymers (resins) through irradiation by a light source (e.g. UV laser). Through a laser beam or a digital light projector, the specific pattern defined by the CAD file is cast over the liquid formulation (Figure 3). The light source supplies the energy required for promoting cross-linking of the polymeric chains, thus leading to the formation of solid layers with a defined resistance, the first one adhering to the build plate. Subsequently, the plate is lowered, the first layer is coated with another fraction of liquid resin, and the curing step is repeated. Therefore, printed items are generally built bottom-up from a build plate that is positioned just below the surface of the liquid. However, a top-down approach was recently proposed, wherein the light is projected from underneath, through a transparent, non-adhering plate. In this case, the build plate is dipped in the liquid resin from above. Although up-to-bottom built structures are subject to higher stresses in that they need to be separated from the bottom build plate after each deposition step, this approach enables the use of smaller amounts of resin, better protection of the object surface from the environment and attainment of a smoother surface.

In view of its suitability for fabrication of precise geometries and internal architectures with details in the micrometer range, SLA is particularly useful in the manufacturing of scaffolds. Indeed, it yields printed objects having up to $20 \mu \mathrm{m}$ resolution, as compared with the $50-200 \mu \mathrm{m}$ range granted by other additive manufacturing techniques, along with high precision and smooth surfaces. However, post-curing with UV light is often required to improve the mechanical properties of the printed objects. The thickness of deposited layers is determined by the viscosity and spreading of the liquid resin employed and the energy of the light, which is mainly controlled by the power and scanning speed for laser systems and by the exposure time for projection systems, respectively. 
The main challenge for SLA technique is related to the limited availability of suitable photopolymers and their quite complex kinetics of curing reactions. Very few materials have been developed so far, and most of them are expensive, toxic, smelly and need to be shielded from light to avoid premature polymerization. Moreover, none is categorized as GRAS and could safely be used for the manufacturing of drug products. Only recently, some biodegradable resins have been identified (e.g. PCL, chitosan) and proposed for fabrication of scaffolds ${ }^{75,76}$. However, since the temperature increase during printing is limited, this technique has a great potential for processing of thermally labile drugs. The few applications of 3D printing based on SLA are summarized in Table 4.

\section{Regulatory perspectives}

Beyond the identification of major targets and development of appropriate techniques for fabrication of drug products, the main challenge for personalized pharmacological therapy would most likely be related to the regulatory issues involved ${ }^{78}$. These may primarily concern health hazards and safety aspects resulting, for instance, from the use of fine powders, organic solvents and irradiation, as well as from possible formation of unknown degradation products derived from high-temperature processing even of already approved materials. Approval of a sufficiently broad variety of thermoplastic polymers and liquid resins to be used in FDM and SLA, respectively, also constitutes a fundamental step that may strongly limit profitable exploitation of $3 \mathrm{D}$ printing in the manufacturing of medicines. Moreover, the actual possibility of undertaking personalized therapy would necessarily depend upon implementation of production models that may enable to efficiently turn the therapeutic needs of individual patients into small batches of appropriate drug products. It is well known that the FDA regulatory approach is currently based on mass production, standardization and batch validation. So, the vast majority of rules applied so far would hold poor promise for the manufacturing of customized medicines. In this respect, FDA has started to consider the impact of $3 \mathrm{D}$ printing on the production of medical devices. It is established that all of them, 
including those produced by additive manufacturing techniques, have to meet the same quality and compliance requirements (i.e. Quality System). Since regulation addresses many different types of devices, it cannot provide specific prescriptions for each fabrication process and rather sets out a framework to ensure that these products consistently meet applicable specifications. Therefore, the trend is to include 3D printed devices under the existing regulations while evaluating similarities and differences over traditionally manufactured products and identifying, through a joint work with manufacturers, the most critical points that need to strictly be controlled. Such a policy led to the drafting of shared Technical Considerations for Additive Manufactured Devices that have recently been published ${ }^{79}$.

With respect to $3 \mathrm{D}$ printed drug products, no tangible progress has been made so far, although FDA is presently engaged in a workable regulatory platform that promotes innovation while ensuring accuracy by issuing discussion papers, holding workshops and collaborating with stakeholders. Indeed, the exploitation of 3D printing techniques for the manufacturing of drug products represents a very challenging subject. For instance, depending on the site where the printing process is run (e.g. compounding pharmacy, hospital pharmacy, pharmaceutical industry), the resulting product should be classified among individual extemporaneous, hospital or industrial preparations, and each of them might have to follow specific regulatory paths. On the other hand, independent of the fabrication site, their quality must be ensured. Therefore, all aspect entailed by the manufacturing process has to be comprehensively considered such as hardware, software, raw materials (e.g. filaments) and their source, operators and training, responsibilities, outcomes and quality controls. Moreover, when the $3 \mathrm{D}$ printing process is carried out at the point of care, high-quality software and hardware supplied by specialized companies (e.g. printers allocated within a high-controlled production chamber), specifically developed for pharmaceutical use, would be needed.

In the meantime, the first $3 \mathrm{D}$ printed tablet, Spritam $^{\circledR}$, fabricated by powder deposition-based Aprecia Zipdose ${ }^{\circledR}$ technology, was approved in summer 2015. This product is available in different strengths up to $1000 \mathrm{mg}$ and enables a new mode of administering anti-epilepsy drug levetiracetam. 
Its goal, however, is only marginally connected with personalization. In this case, 3D printing was indeed exploited for the purpose of fabricating a porous dosage form with high drug load, able to fast disintegrate in a small amount of liquid, which could be critical to attain by traditional manufacturing techniques. Hence, it deals with a dosage form produced on a large-scale and approved via the regulatory procedure currently in use. A recent study also demonstrated bioequivalence of this product in the fasted state to the conventionally fabricated immediate-release tablets available on the market ${ }^{80}$. 


\section{References}

1. Pham DT, Gault RS 1998. A comparison of rapid prototyping technologies. Int J Mach Tools Manuf 38:1257-1287.

2. Gibson I, Rosen DW, Stucker B 2010. Additive Manufacturing Technologies: rapid prototyping to direct digital manufacturing, 2nd ed., New York: Springer.

3. van Wijk AJM, van Wijk I 2015. 3D Printing with Biomaterials: towards a Sustainable and Circular Economy, Amsterdam: IOS press.

4. Berman B 2012. 3-D printing: The new industrial revolution. Bus Hor 55: 155-162.

5. Gebler M, Schoot Uiterkamp AJM, Visser C 2014. A global sustainability perspective on 3D printing technologies. Energy Policy 74:158-167.

6. Jain KK 2009. Textbook of personalized medicine, Humana Press, 2nd ed., Basel: Humana Press p 1-3.

7. Li YY, Jones SJM 2012. Drug repositioning for personalized medicine. Genome Med 4: $27-40$.

8. Hamburg M 2013. Paving the way for personalized medicine. FDA's role in a new era of product development,

US. https://www.fda.gov/downloads/ScienceResearch/SpecialTopics/PersonalizedMedicine/UC M372421.pdf

9. O' Donnell JC 2013. Personalized medicine and the role of health economics and outcomes research: issues, applications, emerging trends, and future research. Value Health 16:S1S3.

10. http://www.personalizedmedicinecoalition.org/, accessed on October 27th 2016.

11. Alomari M, Mohamed FH, Basit AW, Gaisford S 2015. Personalised dosing: Printing a dose of one's own medicine. Int J Pharm 494:568-77.

12. Kurzrock R, Stewart DJ 2015. Click chemistry, 3D-printing, and omics: the future of drug development. Oncotarget 7:2155-2158. 
13. Alhnan MA, Okwuosa TC, Sadia M, Wan KW, Ahmed W, Arafat B 2016. Emergence of 3D Printed Dosage Forms: Opportunities and Challenges. Pharm. Res. 33:1817-1832.

14. Norman J, Madurawe RD, Moore CMV, Khan MA, Khairuzzamana A 2017. A new chapter in pharmaceutical manufacturing: 3D-printed drug products. Adv Drug Deliv Rev 108:39-50.

15. Rengier F, Mehndiratta A, von Tengg-Kobligk H, Zechmann CM, Unterhinninghofen R, Kauczor HU, Giesel FL 2010. 3D printing based on imaging data: review of medical applications. Int J Comput Assist Radiol Surg 5:335-341.

16. Martelli N, Serrano C, Van Den Brink H, Pineau J, Prognon P, Borget I, El Batti S 2016. Advantages and disadvantages of 3-dimensional printing in surgery: a systematic review. Surg 159:1485-1500.

17. Leong KF, Cheah CM, Chua CK 2003 Solid freeform fabrication of three dimensional scaffolds for engineering replacement tissues and organs. Biomaterials 24:2363-2378.

18. Lam CXF, Mo XM, Teoh SH, Hutmacher DW 2002. Scaffold development using 3D printing with a starch-based polymer. Mater Sci Eng C 20:49-56.

19. Hutmacher DW, Sittinger M, Risbud MV 2004. Scaffold-based tissue engineering: rationale for computer-aided design and solid free-form fabrication systems. Trends Biotechnol 22:354-362.

20. Wu C, Luo Y, Cuniberti G, Xiao Y, Gelinsky M 2011. Three-dimensional printing of hierarchical and tough mesoporous bioactive glass scaffolds with a controllable pore architecture, excellent mechanical strength and mineralization ability. Acta Biomater 7:2644-2650.

21. Korpela J, Kokkari A, Korhonen H, Malin M, Närhi T, Seppälä J 2013. Biodegradable and bioactive porous scaffold structures prepared using fused deposition modeling. J Biomed Mater Res B Appl Biomater 101:610-619. 
22. Prasad LK, Smyth H 2015. 3D Printing technologies for drug delivery: a review. Drug Dev Ind Pharm 13:1-13.

23. Jonathan G, Karim A 2016. 3D printing in pharmaceutics: a new tool for designing customized drug delivery systems. Int J Pharm 499:376-394.

24. Sandler N, Preis M 2016. Printed drug-delivery systems for improved patient treatment. Trends Pharmacol Sci 37:1070-1080.

25. Preis M, Öblom H 2017. 3D-printed drugs for children-are we ready yet?. AAPSPharmSciTech 18:303-308.

26. Zhang J, Feng X, Patil H, Tiwari RV, Repka MA 2016. Coupling 3D printing with hotmelt extrusion to produce controlled-release tablets. Int. J. Pharm. 519:186-197.

27. Sun Y, Soh S 2015. Printing tablets with fully customizable release profiles for personalized medicine. Adv Mater 27:7847-7853.

28. Lim SH, Chia SMY, Kang L, Yap KYL 2015. Three-dimensional printing of carbamazepine sustained-release scaffold. J Pharm Sci 105:2155-2163.

29. Yu DG, Zhu LM, Branford-White CJ, Yang XL 2008. Three-dimensional printing in pharmaceutics: promises and problems. J Pharm Sci 97:3666-3690.

30. Sachs E, Cima MJ, Cornie J, Brancazio D, Bredt J, Curodeau A, Esterman M, Fan T, Harris C, Kremmin K, Lee SJ, Pruitt B, Williams P 1992. Three dimensional printing: rapid tooling and prototypes directly from CAD model. J Eng Ind 114:481-488.

31. Wu BM, Borland SW, Giordano RA, Cima LG, Sachs EM, Cima MJ 1996. Solid free-form fabrication of drug delivery devices. J Control Release 40:77-87.

32. Sachs E, Wylonis E, Allen S, Cima M, Guo H 2000. Production of injection molding tooling with conformal cooling channels using the three dimensional printing process. Polym Eng Sci 40:1232-1247. 
33. Lee KJ, Kang A, Delfino JJ, West TG, Chetty D, Monkhouse DC, Yoo J 2003. Evaluation of critical formulation factors in the development of a rapidly dispersing captopril oral dosage form. Drug Dev Ind Pharm 29:967-979.

34. Yu DG, Shen XX, Branford-White C, Zhu LM, White K, Yang XL 2009. Novel oral fastdisintegrating drug delivery devices with predefined inner structure fabricated by threedimensional printing. J Pharm Pharmacol 61:323-329.

35. Yu DG, Branford-White C, Yang YC, Zhu LM, Welbeck EW, Yang XL 2009. A novel fast disintegrating tablet fabricated by three-dimensional printing. Drug Dev Ind Pharm $35: 1530-1536$.

36. Yu DG, Yang XL, Huang WD, Liu J 2007. Wang YG, Xu H, Tablets with material gradients fabricated by three-dimensional printing. J Pharm Sci 96:2446-2456.

37. Wu G, Wu W, Zheng Q, Li J, Zhou J, Hu Z 2014. Experimental study of PLLA/INH slow release implant fabricated by three dimensional printing technique and drug release characteristics in vitro. Biomed Eng Online 13:97-107.

38. Gupta MK, Meng F, Johnson BN, Kong YL, Tian L, Yeh YW, Masters N, Singamaneni S, McAlpine MC 2015. 3D printed programmable release capsules. Nano Lett 15:5321-5329.

39. Wang CC, Tejwani MR, Roach WJ, Kay JL, Yoo J, Surprenant HL, Monkhouse DC, Pryor TJ 2006. Development of near zero-order release dosage forms using three-dimensional printing (3-DPTM) technology. Drug Dev Ind Pharm 32:367-376.

40. Yu DG, Branford-White C, Ma ZH, Zhu LM, Li XY, Yang XL 2009. Novel drug delivery devices for providing linear release profiles fabricated by 3DP. Int J Pharm 370:160-166.

41. Huang W, Zheng Q, Sun W, Xu H, Yang X 2007. Levofloxacin implants with predefined microstructure fabricated by three-dimensional printing technique. Int J Pharm 339:33-38.

42. Wu W, Zheng Q, Guo X, Huang W 2009. The controlled-releasing drug implant based on the three dimensional printing technology: fabrication and properties of drug releasing in vivo. Journal of Wuhan University of Technology-Mater. Sci. Ed 24:977-981. 
43. Wu W, Zheng Q, Guo X, Sun J, Liu Y 2009. A programmed release multi drug implant fabricated by three-dimensional printing technology for bone tuberculosis therapy. Biomed Mat 4:1-10.

44. Lin S, Chao PY, Chien YW, Sayani A, Kumar S, Mason M, West T, Yang A, Monkhouse D 2001. In vitro and in vivo evaluations of biodegradable implants for hormone replacement therapy: effect of system design and PK-PD relationship. AAPS PharmsciTech 2:55-65.

45. Rowe CW, Katstra WE, Palazzolo RD, Giritlioglu B, Teung P, Cima MJ 2000. Multimechanism oral dosage forms fabricated by three dimensional printing. J Control Release 66:11-17.

46. Katstra WE, Palazzolo RD, Rowe CW, Giritlioglu B, Teung P, Cima MJ 2000. Oral dosage forms fabricated by Three Dimensional Printing. J Control Release 66:1-9.

47. Stephens B, Azimi P, El Orch, Ramos T 2014. Ultrafine particle emissions from desktop 3D printers. Atmos Environ 79:334-339.

48. Goyanes A, Buanz ABM, Basit AW, Gaisford S 2014. Fused-filament 3D printing (3DP) for fabrication of tablets. Int J Pharm 476:88-92.

49. Goyanes A, Buanz ABM, Hatton GB, Gaisford S, Basit AW 2015. 3D printing of modified-release aminosalicylate (4-ASA and 5-ASA) tablets. Eur J Pharm Biopharm 89:157-162.

50. Goyanes A, Kobayashi M, Martínez-Pacheco R, Gaisford S, Basit AW 2016. Fusedfilament 3D printing of drug products: microstructure analysis and drug release characteristics of PVA-based caplets. Int J Pharm 514:290-295.

51. Skowyra J, Pietrzak K, Alhnan MA 2015. Fabrication of extended-release patient-tailored prednisolone tablets via fused deposition modelling (FDM) 3D printing. Eur J Pharm Sci 68:11-17. 
52. Holländer J, Genina N, Jukarainen H, Khajeheian M, Rosling A, Mäkilä E, Sandler N 2016. Three-dimensional printed PCL-based implantable prototypes of medical devices for controlled drug delivery. J Pharm Sci 105:2665-2676.

53. Genina N, Holländer J, Jukarainen H, Mäkilä E, Salonen J, Sandler N 2016. Ethylene vinyl acetate (EVA) as a new drug carrier for 3D printed medical drug delivery devices. Eur $\mathrm{J}$ Pharm Sci 90:53-63.

54. Melocchi A, Parietti F, Maroni A, Foppoli A, Gazzaniga A, Zema L 2016. Hot-melt extruded filaments based on pharma-grade polymers for 3D printing by Fused Deposition Modeling. Int J Pharm 509:255-263.

55. Pietrzak K, Isreb A, Alhnan MA 2015. A flexible-dose dispenser for immediate and extended release 3D printed tablets. Eur J Pharm Biopharm 96:380-387.

56. Melocchi A, Parietti F, Loreti G, Maroni A, Gazzaniga A, Zema L 2015. 3D printing by fused deposition modeling (FDM) of a swellable/erodible capsular device for oral pulsatile release of drugs. J Drug Deliv Sci Technol 30 Part B:360-367.

57. Sadia M, Sośnicka A, Arafat B, Isreb A, Ahmed W, Kelarakis A, Alhnan MA 2016. Adaptation of pharmaceutical excipients to FDM 3D printing for the fabrication of patienttailored immediate release tablets. Int. J. Pharm 513:659-668.

58. Okwuosa TC, Pereira BC, Arafat B, Cieszynska M, Isreb A, Alhnan MA 2017. Fabricating a shell-core delayed release tablet using dual FDM 3D printing for patient-centred therapy. Pharm Res 34:427-437.

59. Alhijjaj M, Belton P, Sheng Q 2016. An investigation into the use of polymer blends to improve the printability of and regulate drug release from pharmaceutical solid dispersions prepared via fused deposition modeling (FDM) 3D printing. Eur J Pharm Biopharm 108:111-125.

60. Aho J, Boetker JP, Baldursdottir S, Rantanen J 2015. Rheology as a tool for evaluation of melt processability of innovative dosage forms. Int J Pharm 494:623-642. 
61. Goyanes A, Wang J, Buanz A, Martínez-Pacheco R, Telford R, Gaisford S, Basit AW 2015. 3D Printing of medicines: engineering novel oral devices with unique design and drug release characteristics. Mol. Pharm. 12:4077-4084.

62. Boetker J, Water JJ, Aho J, Arnfast L, Bohr A, Rantanen J 2016. Modifying release characteristics from 3D printed drug-eluting products. Eur J Pharm Sci 90:47-52.

63. Malone E, Lipson H 2007. Fab@Home: the personal desktop fabricator kit. Rapid Prototyp J 13: 245-255.

64. Weisman JA, Nicholson JC, Tappa K, Jammalamadaka U, Wilson CG, Mills DK 2015. Antibiotic and chemotherapeutic enhanced three-dimensional printer filaments and constructs for biomedical applications. Int J Nanomed 10:357-370.

65. Yi HG, Choi YJ, Kang KS, Hong JM, Pati RG, Park MN, Shim IK, Lee CM, Kim SC, Cho DW 2016. A 3D-printed local drug delivery patch for pancreatic cancer growth suppression. J Control Release 238:231-241.

66. Goyanes A, Det-Amornrat U, Wang J, Basit AW, Gaisford S 2016. 3D scanning and 3D printing as innovative technologies for fabricating personalized topical drug delivery systems. J Control Release 234:41-48.

67. Goyanes A, Chang H, Sedough D, Hatton GB, Wang J, Buanz A, Gaisford S, Basit AW. 2015. Fabrication of controlled-release budesonide tablets via desktop (FDM) 3D printing. Int J Pharm 496:414-420.

68. Goyanes A, Robles Martinez P, Buanz A, Basit AW, Gaisford S 2015. Effect of geometry on drug release from 3D printed tablets. Int J Pharm 494:657-663.

69. Okwuosa TC, Stefaniak D, Arafat B, Isreb A, Wan KW, Alhnan MA 2016. A Lower Temperature FDM 3D Printing for the manufacture of patient-specific immediate release tablets. Pharm Res 33:2704-2712.

70. Khaled SA, Burley JC, Alexander MR, Roberts CJ 2014, Desktop 3D printing of controlled release pharmaceutical bilayer tablets. Int J Pharm 461:105-111. 
71. Khaled SA, Burley JC, Alexander MR, Yang J, Roberts CJ 2015. 3D printing of tablets containing multiple drugs with defined release profiles. Int J Pharm 494:643-650.

72. Khaled SA, Burley JC, Alexander MR, Yang J, Roberts CJ 2015. 3D printing of five-inone dose combination polypill with defined immediate and sustained release profiles. $\mathbf{J}$ Control Release 10:308-314.

73. Melchels FPW, Feijen J, Grijpma DW 2010. A review on stereolithography and its applications in biomedical engineering. Biomaterials 31:6121-6130.

74. Skoog SA, Goering PL, Narayan RJ 2014. Stereolithography in tissue engineering. J Mater Sci Mater Med 25:845-856.

75. Elomaa L, Teixeira S, Hakala R, Korhonen H, Grijpma DW, Seppälä JV 2011. Preparation of poly( $\varepsilon$-caprolactone)-based tissue engineering scaffolds by stereolithography. Acta Biomater 7:3850-3856.

76. Gill AA, Claeyssens F 2011. 3D structuring of biocompatible and biodegradable polymers via stereolithography. Methods mol biol 695:309-321.

77. Wang J, Goyanes A, Gaisford S, Basit AW 2016. Stereolithographic (SLA) 3D printing of oral modified-release dosage forms. Int J Pharm 503:207-212.

78. Di Prima M, Coburn J, Hwang D, Kelly J, Khairuzzaman A, Ricles L 2016. Additively manufactured medical products - the FDA perspective. 3D Printing in Medicine 2:1-6.

79. http://www.fda.gov/MedicalDevices/ProductsandMedicalProcedures/3DPrintingofMedical Devices/ucm500548.htm, accessed on February $27^{\text {th }} 2016$.

80. Boudriau S, Hanzel C, Massicotte J, Sayegh L, Wang J, Lefebvre M 2016. Randomized comparative bioavailability of a novel three-dimensional printed fast-melt formulation of levetiracetam following the administration of a single 1000-mg dose to healthy human volunteers under fasting and fed conditions. Drugs R D 16:229-238. 
Table 1: classification of the main additive manufacturing techniques

\begin{tabular}{|l|l|l|l|}
\hline \multicolumn{1}{|c|}{ TECHNIQUE } & \multicolumn{1}{|c|}{ SUBSTRATE } & MECHANISM OF LAYERING & ADDITIVE PROCESS \\
\hline $\begin{array}{l}\text { FUSED DEPOSITION } \\
\text { MODELING }\end{array}$ & $\begin{array}{l}\text { filament } \\
\text { (thermoplastic polymer) }\end{array}$ & $\begin{array}{l}\text { melting/softening by an heated } \\
\text { nozzle }\end{array}$ & extrusion \\
\hline $\begin{array}{l}\text { ELECTRON BEAM DIRECT } \\
\text { MANUFACTURING }\end{array}$ & $\begin{array}{l}\text { wire } \\
\text { (metal) }\end{array}$ & melting by an electron beam & direct energy deposition \\
\hline $\begin{array}{l}\text { SELECTIVE LASER } \\
\text { SINTERING }\end{array}$ & solid particles & melting by laser & solidification of powder \\
\cline { 2 - 4 } $\begin{array}{l}\text { THREE DiMENSIONAL } \\
\text { PRINTING }\end{array}$ & binding by wetting & photopolymerization \\
\hline STEREOLITHOGRAPHY & $\begin{array}{l}\text { liquid } \\
\text { (photopolymer) }\end{array}$ & binding by UV ray & sheet lamination \\
\hline $\begin{array}{l}\text { LAMINATED OBJECT } \\
\text { MANUfACTURING }\end{array}$ & $\begin{array}{l}\text { sheets } \\
\text { (paper, metal, plastics) }\end{array}$ & cutting by laser & \\
\hline
\end{tabular}


Table 2: overview of dosage forms fabricated by 3D printing based on solidification of powder

\begin{tabular}{|c|c|c|c|c|}
\hline Product & Performance & Starting materials & Equipment & References \\
\hline \multirow[b]{2}{*}{$\begin{array}{c}\text { Implantable } \\
\text { systems/inserts }\end{array}$} & \multirow{4}{*}{$\begin{array}{l}\text { Immediate, prolonged, } \\
\text { pulsatile release and } \\
\text { combinations of differing } \\
\text { kinetics }\end{array}$} & $\begin{array}{l}\text { POWDER } \\
\text { PCL, PLA, PLGA }\end{array}$ & \multirow{2}{*}{$\begin{array}{l}\text { Custom-made } \\
\text { (Fochif Mechatronics } \\
\text { Technologies Co. Ltd, } \\
\text { Therics) }\end{array}$} & \multirow[b]{2}{*}{$37,41-44$} \\
\hline & & $\begin{array}{l}\text { BINDING LIQUID } \\
\text { SOLVENT: acetone, ethanol, methanol, water } \\
\text { API: ethinyl estradiol; isoniazid; levofloxacin; } \\
\text { rifampicine }\end{array}$ & & \\
\hline \multirow[b]{2}{*}{ Oral systems } & & $\begin{array}{l}\text { POWDER } \\
\text { colloidal silicon dioxide, HPMC, Kollidon }{ }^{\circledR} \text { SR, lactose, } \\
\text { MCC, PVP,SLS, stearic acid } \\
\text { API: acetaminophen }\end{array}$ & \multirow{2}{*}{$\begin{array}{l}\text { Custom-made } \\
\text { (Fochif Mechatronics } \\
\text { Technologies Co. Ltd, } \\
\text { TheriForm } \\
\text { TM } \text { ) }\end{array}$} & \multirow[b]{2}{*}{$\begin{array}{c}36,39,40 \\
45,46\end{array}$} \\
\hline & & $\begin{array}{l}\text { BINDING LIQUID } \\
\text { SOLVENT: acetone, ethanol, water } \\
\text { BINDER: EC, Eudragit }{ }^{\mathbb{B}} \mathrm{E}, \mathrm{RL} \text { and RS, PVP, TEC, } \\
\text { Tween } 20 \\
\text { API: acetaminophen, diclofenac, chlorpheniramin } \\
\text { maleate, fluorescein disodium salt (tracer) }\end{array}$ & & \\
\hline \multirow[b]{2}{*}{$\begin{array}{l}\text { Orally disintegrating } \\
\text { tablets }\end{array}$} & \multirow[b]{2}{*}{ Immediate and fast release } & $\begin{array}{l}\text { POWDER } \\
\text { colloidal silicon dioxide, crosslinked PVP, lactose, } \\
\text { maltitolo, maltodextrin, mannitol, PVP, } \\
\text { API: acetaminophen }\end{array}$ & \multirow{2}{*}{$\begin{array}{c}\text { Custom-made } \\
\text { (Folichif Mechatronics } \\
\text { Technologies Co. Ltd) }\end{array}$} & \multirow[b]{2}{*}{$33-35$} \\
\hline & & $\begin{array}{l}\text { BINDING LIQUID } \\
\text { SOLVENT: ethanol, phosphate buffer }(\mathrm{pH}=4) \text {, water } \\
\text { BINDER: ascorbic acid, citric acid, EDTA, PVP, Tween } \\
20 \\
\text { API: alizarin yellow (tracer), captopril, methylene blue } \\
\text { (tracer) }\end{array}$ & & \\
\hline
\end{tabular}


Table 3: overview of dosage forms fabricated by 3D printing based on extrusion

\begin{tabular}{|c|c|c|c|c|c|}
\hline & Product & Performance & Starting materials & Equipment & References \\
\hline \multirow{4}{*}{ 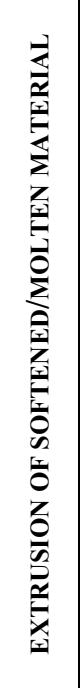 } & $\begin{array}{c}\text { Implantable } \\
\text { systems/Inserts }\end{array}$ & \multirow{2}{*}{ Prolonged release } & $\begin{array}{c}\text { EVA, PCL, PLA, PLGA, PCL } \\
\text { API: 5-fluorouracil, gentamicin sulfate, indomethacin, } \\
\text { methotrexate }\end{array}$ & \multirow{4}{*}{$\begin{array}{l}\text { Commercial } \\
\text { (MakerBot, Prusa } \\
\text { Research) }\end{array}$} & $52,53,64,65$ \\
\hline & Dermal patches & & $\begin{array}{c}\left.\text { PCL, commercial PLA filament (Flex EcoPLA }{ }^{\mathrm{TM}}\right) \text {, } \\
\text { commercial TPU filament }\left(\text { NinjaFlex }{ }^{\mathrm{TM}}\right) \\
\text { API: salicylic acid }\end{array}$ & & 66 \\
\hline & Oral systems & $\begin{array}{l}\text { Immediate, prolonged, } \\
\text { pulsatile, delayed release and } \\
\text { combinations of differing } \\
\text { kinetics }\end{array}$ & $\begin{array}{c}\text { commercial PVA filament, crospovidone, EC, Eudragit }^{\circledR} \\
\text { E, L, RL and RS, low viscosity HPC, HPC, HPMC, } \\
\text { lactose, MCC, PVP, Soluplus }{ }^{\circledR} \text {, TEC, triacetin, tribasic } \\
\text { phosphate, tricalcium phosphate, talc } \\
\text { API: 4-aminosalicylic acid, 5-aminosalicylic acid, } \\
\text { acetaminophen, budesonide, caffeine, captopril, } \\
\text { diclofenac sodium, dipyridamole, fluorescein (tracer), } \\
\text { prednisolone, theophylline }\end{array}$ & & $\begin{array}{l}48,51,55,61 \\
66-69,26,57 \\
50,58\end{array}$ \\
\hline & Capsule shells & Pulsatile release & HPC, PEG & & 56 \\
\hline 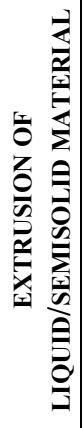 & Oral systems & $\begin{array}{l}\text { Immediate, prolonged release } \\
\text { and combinations of differing } \\
\text { kinetics }\end{array}$ & $\begin{array}{c}\text { croscarmellose sodium, HPMC, lactose, mannitol, MCC, } \\
\text { PVP, sodium starch glycolate, PEG, tromethamine } \\
\text { SOLVENT: acetone, dimethyl sulfoxide, ethanol,water } \\
\text { API: acetylsalicylic acid, atenolol, captopril, glipizide, } \\
\text { guaifenesine, hydrochlorothiazide, nifedipine, } \\
\text { pravastatin, ramipril }\end{array}$ & $\begin{array}{l}\text { Commercial } \\
\text { (Fab@Home, } \\
\text { (RegenHU) }\end{array}$ & $70-72$ \\
\hline
\end{tabular}


Table 4: overview of dosage forms fabricated by 3D printing based on stereolithography

\begin{tabular}{|c|c|c|c|c|}
\hline Product & Performance & Starting materials & Equipment & References \\
\hline Oral systems & Prolonged release & $\begin{array}{l}\text { DPPO, PEG, PEGDA } \\
\text { API: 4-aminosalicylic acid, acetaminophen }\end{array}$ & \multirow{2}{*}{$\begin{array}{c}\text { Commercial } \\
\text { (Formlabs Inc.) }\end{array}$} & 77 \\
\hline Dermal patches & Prolonged release & $\begin{array}{l}\text { DPPO, PEG, PEGDA } \\
\text { API: salicylic acid }\end{array}$ & & 66 \\
\hline
\end{tabular}


Figure 1: outline of common steps generally entailed by a 3D printing process

Figure 2: outline of 3D-printed drug products proposed in the scientific literature (references in brackets)

Figure 3: outline of equipment relevant to 3D printing based on powder deposition, extrusion of molten/softened or semisolid materials and stereolithography 


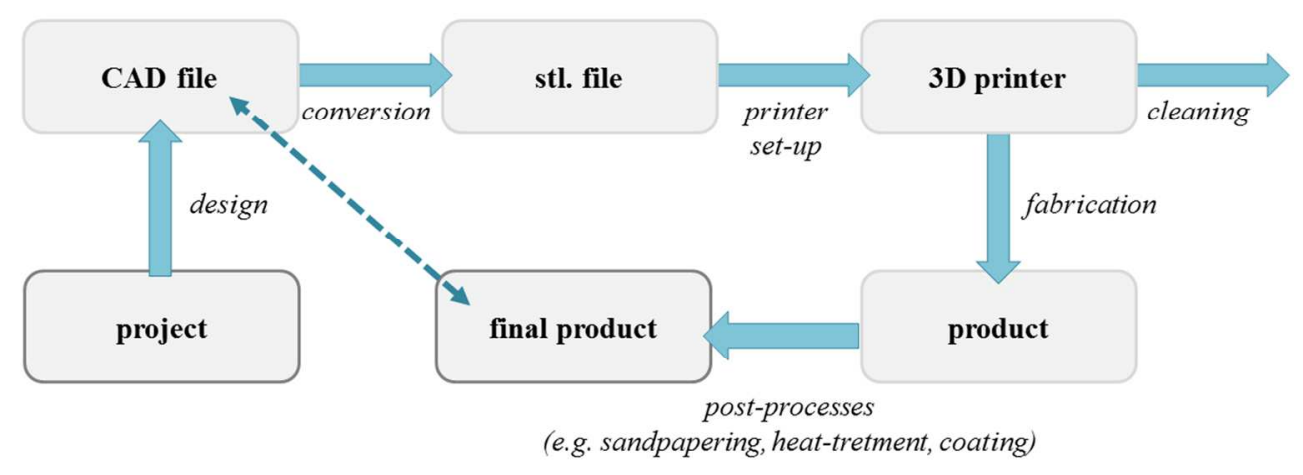

Figure 1: outline of common steps generally entailed by a 3D printing process

$69 \times 25 \mathrm{~mm}(600 \times 600 \mathrm{DPI})$ 


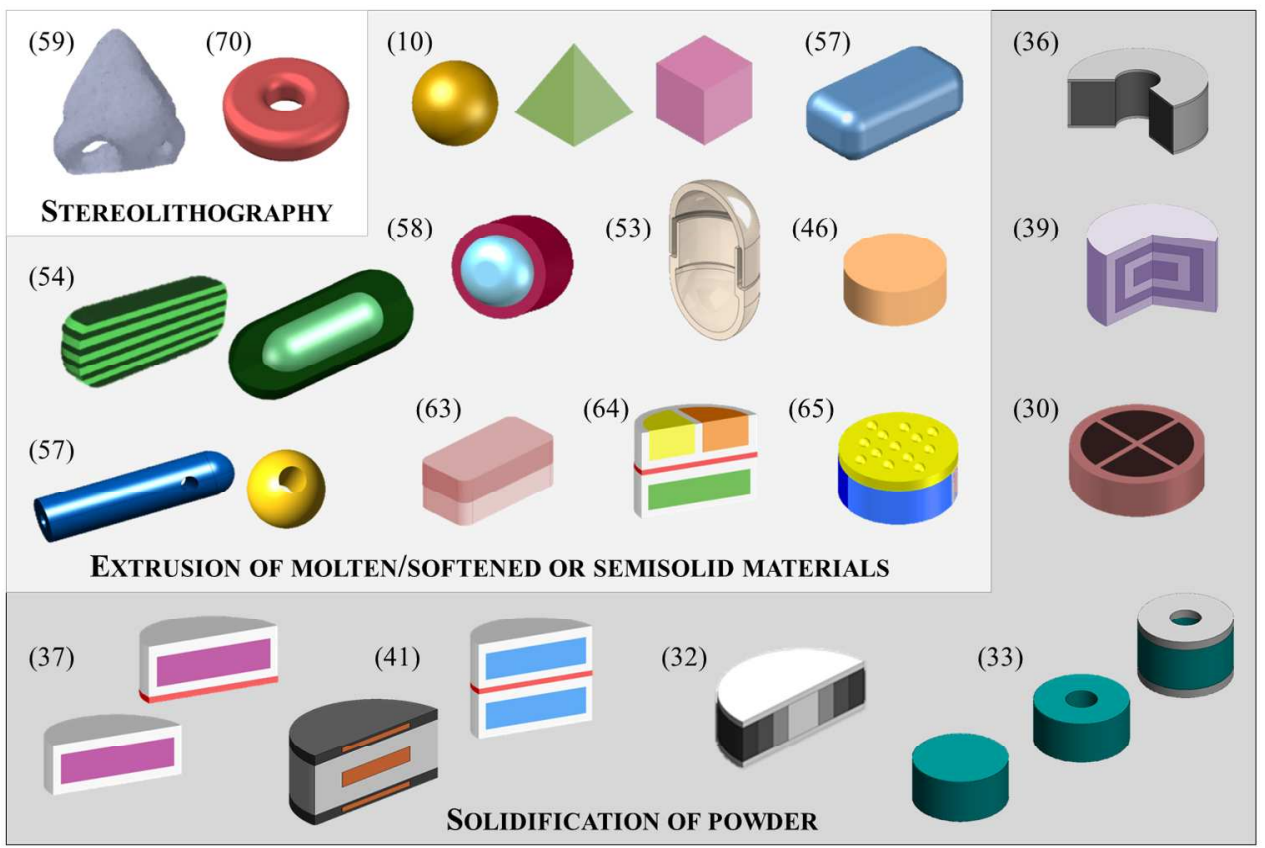

Figure 2: outline of 3D-printed drug products proposed in the scientific literature (references in brackets) $129 \times 88 \mathrm{~mm}(600 \times 600 \mathrm{DPI})$ 


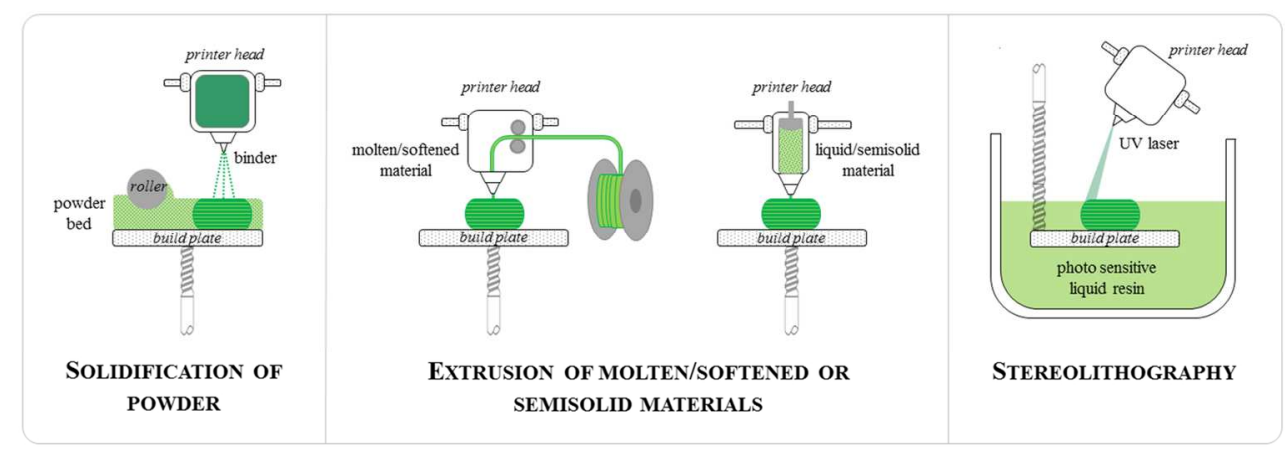

Figure 3: outline of equipment relevant to 3D printing based on powder deposition, extrusion of molten/softened or semisolid materials and stereolithography

$68 \times 24 \mathrm{~mm}(600 \times 600 \mathrm{DPI})$ 